\title{
Earnings-based compensation contracts under asymmetric information*
}

\author{
Anton Miglo \\ University of Guelph, Department of Economics, Guelph, Ontario, Canada, \\ N1G 2W1, tel. (519) 824-4120, ext. 53054, e-mail: amiglo@uoguelph.ca. \\ 2008, forthcoming in The Manchester School
}

\begin{abstract}
We analyze a model with two-dimensional asymmetric information in which the employer has better information about the firm's earnings potential and the employee is subject to moral hazard. The employee's contract consists of an annual bonus and stock options. We focus on two issues: how different degrees of asymmetric information about short-term earnings versus long-term earnings affect optimal contracts and second, if a signalling equilibrium exists, what information concerning the firm's performance profile over time can be conveyed by the choice of contract. We show that if the extent of long-term (short-term) asymmetric information is larger, short-term (long-term) compensation prevails. With regard to signalling, we show that firms offering more options have higher short-term performance and lower long-term performance. This provides new insights into the structure of earnings-based compensation.
\end{abstract}

JEL classification: D82, J33, M12, M52

${ }^{*}$ I would like to thank Jeffrey Coles, Jonathan Cohn, Anand Goel, Thomas Lys and 2007 Financial Management Association Annual Meeting participants for useful comments. I also appreciate the editing assistance of Peter Huffman and Conor Meade. 


\section{Introduction}

This paper analyzes the structure of earnings-based compensation contracts (long-term versus short-term) and is based on the existence of ex-ante asymmetric information between an employer and a worker. The literature dealing with asymmetric information related to the employer-worker relationship usually assumes that private information is held by potential workers (such as their ability level, for instance). ${ }^{1}$ In the present paper, an employer has private information about a firm's earnings potential. ${ }^{2}$ We argue that this significantly affects the optimal structure of earnings-based compensation contracts which have been used in an increasing number of contracts in recent years and which remain puzzling from a moral hazard or agency theory viewpoint. $^{3}$ The following anecdotal evidence illustrates employers' usage of private information when designing the structure of compensation contracts. General Dynamics and other defence firms (very successful at the time) increased stock options when they began to receive information about the end of defence spending linked to the end of Cold War (Dial and Murphy, 1995) since cash bonuses became too costly.

We analyze a signaling game where private information is two-dimensional: the employers have private information about short-term and long-term expected earnings. ${ }^{4}$ The degree of asymmetric information regarding shortterm and long-term earnings may vary. Asymmetry regarding long-term earnings is high when information about short-term prospects is publicly available while long-term performance is unknown. This may be the case when short-term performance relies on past decisions which are publicly observable while long-term performance may depend on strategic decisions which are not disclosed. Long-term asymmetry may also be high when

\footnotetext{
${ }^{1}$ See, for example, Spence (1973), Salop and Salop (1976), Berkovitch (1986), and Handy and Katz (1998).

${ }^{2}$ Lambert (2001) noticed that a set-up where the principal (employer) has private information about strategic varibales is interesting for analyzing compensation related issues. Existing literature on implicit contracts (pioneered by Azariadis, 1983) studies similar situations. This literature analyzes the level of unemployment, the problem of wage rigidity and other macroeconomic questions. The structure of compensation contracts is not usually the focus.

${ }^{3}$ See, among others, Lambert (2001) and Yermack (1995, 1997).

${ }^{4}$ See Miglo (2007, 2008) and Miglo and Zenkevich (2006) for the effect of long-term private information concerning future earnings on capital structure.
} 
there is asymmetric information regarding the entrepreneurial skills of topmanagement. Asymmetric information regarding short-term earnings is high when the firm has important private short-term information like delays in production, allowance for bad debts, recognition of sales not yet shipped, estimation of pension liabilities, capitalization of leases and marketing expenses, delay in maintenance expenditures while there is little asymmetry regarding long-term information. This can also be the case when the quality of accounting technology is low or when monitoring is very expensive.

If a separating equilibrium does not exist, equilibrium is pooling where firms use the same compensation policy. We show that if the extent of longterm asymmetric information is larger, short-term compensation prevails. If short-term private information is more important, long-term compensation prevails. Intuitively, firms will try to avoid adverse selection costs by using contracts contingent on earnings with less uncertainty. This is consistent with evidence provided by Bushman, Chen, Engel and Smith (2004). The authors show that stock options are inversely related to the timeliness of accounting numbers or to the extent to which current earnings incorporate value-relevant information. If the asymmetry regarding current earnings is high, the relationship between current earnings and firm value is low.

With regard to signalling, we show that a separating equilibrium does not exist if the extent of asymmetric information regarding the magnitude of total earnings is high. For instance, some firms may expect much higher earnings than others in both the short and long term. In this case firms with low expected earnings mimic the compensation policy of firms with relatively high expected earnings mirroring the famous "lemon" adverse selection effect (Akerloff, 1970). However, if asymmetric information regarding the magnitude of total earnings is small while asymmetric information regarding the temporal distribution of earnings is high a separating equilibrium may exist where firms with high short-term expected earnings may issue more options than firms with low short-term expected earnings. This equilibrium also explains why short-term earnings-based compensation may prevail over long-term compensation and why the use of stock options may be negatively correlated with a firm's future performance (contrary to the usual moral hazard predictions). This phenomenon is puzzling from the standard moral hazard point of view while it has been observed in practice (see, for instance, Yermack (1997) and Cheng and Farber (2006)).

The rest of this paper is organized as follows. The basic model is described in Section 2. Sections 3 and 4 analyze the optimal design of compensation 
contracts under asymmetric information. The model implications, empirical evidence and suggestions of possible strategies for testing the results are discussed in Section 4. The conclusion is presented in Section 5.

\section{Model.}

Consider a firm with a two-stage production process. In each stage $t=1,2$, earnings $\widetilde{r}_{t}$ depend on a worker's effort and the firm's productivity. For simplicity assume that there are two levels of effort $e_{t}$. If $e_{t}=0$ then $\widetilde{r}_{t}=0$. If $e_{t}=1$, production can either be successful or unsuccessful. If the former is the case, $\widetilde{r}_{t}=1$ and if the latter is the case, $\widetilde{r}_{t}=0$. There are two types of firms. For type $g$ ("good") the probability of success in the first period equals $\theta_{g 1}$ and that in the second period equals $\theta_{g 2}$. Type $b$ ("bad") has parameters $\theta_{b 1}$ and $\theta_{b 2}$. By definition, $g$ has better overall performance than $b: v_{g}>v_{b}$, where $v_{x}=\theta_{x 1}+\theta_{x 2}$ is firm $x$ 's total expected earnings over the two periods. Let $\mu_{0}$ be the proportion of type $g$ firms, $0<\mu_{0}<1$. Let $\widehat{\theta}_{t}=\theta_{g t} \mu_{0}+\theta_{b t}\left(1-\mu_{0}\right)$ ("average firms' performance in period $\left.t^{\prime \prime}\right)$. In each period, $e_{t}=1$ costs the Worker $c$. We assume that the $\theta$ 's are restricted to the interval $(c, 1]$, which implies that $e_{t}=1$ is socially optimal and production is profitable in each period. Stages are technologically dependant. If $e_{1}=0$ then, regardless the effort in the second period, $r_{2}=0$.

At the beginning of each period the Employer (the firm's owner or the Directors Board) offers a contract to the Worker. The Worker may accept or reject the offer. If the offer is rejected then the payoff to both parties equals 0 . If the offer is accepted then the Worker chooses $e_{1}$. The same scenario repeats in the second period after the parties observe $r_{1}$. The Worker's payoff is a fraction of the firm's profit. The first-period contract contains two numbers: an annual bonus representing a fraction $\left(f_{1}\right)$ of first-period earnings and a portfolio of stock options which give the Worker the right to purchase a fraction $(f)$ of the firm's shares (it is assumed for simplicity that the exercise price equals 0 ) at the end of the first period. ${ }^{5}$ Selling

\footnotetext{
${ }^{5}$ The assumption concerning zero exercise prices is not crucial. Also, the introduction of more kinds of compensation such as restricted stocks, long-term incentive plans or retirement plans in the contract will not alter the results. Both these points hold true as long as long-term compensation depends more on the firm's second-period earnings than on first-period earnings. This is even the case for restricted stocks because they usually have different timing constraints (Murphy, 1999).
} 
options at the beginning of the first period is prohibited. Companies often put restrictions of this nature on the sale of options at the beginning of a workers employment. Typically, options are not directly tradeable and secondly they become exercisable (i.e. the recipient is given the right to buy stocks) over time (Murphy, 1999). The second-period contract contains only the annual bonus of the Worker which is represented by a fraction of the second-period profit $\left(f_{2}\right)$. We assume limited liability for both parties:

$$
\begin{gathered}
0 \leq f_{t} \leq 1 \text { and } 0 \leq f \leq 1 \\
f_{2}+f \leq 1
\end{gathered}
$$

If $f_{1}<f$ the equity-based component (long-term incentive) prevails in the first-period contract and vice versa. Let $\alpha_{t}$ denote the proportion of earnings retained by the Employer in period $t$. Clearly,

$$
\alpha_{1}=1-f_{1} \text { and } \alpha_{2}=1-f_{2}-f
$$

There exists universal risk-neutrality in this economy. For simplicity it is assumed that the Worker's reservation payoff in each period equals 0 . The second-period incentive constraint for the Worker is that his expected second-period payoff is not smaller than $c$. We also assume the existence of a perfect capital market for shares. At the end of first period the Worker can sell a portion of their shares. We denote the remaining fraction of shares by $f_{n}$. In the first period, the Worker's incentive constraint (assuming that the second-period incentive constraint holds) is that his expected net payoff from supplying $e_{1}=1$ (which includes the first-period bonus, the value of shares sold at the end of the first period, and the second-period payoff minus $c$ ) is not less than $c .{ }^{6}$ The Employer knows the firm's type, but the Worker does not. The distribution of types is common knowledge. The contracts are enforceable at no cost.

The sequence of events is illustrated in Figure 1. We assume that the firm's type is revealed to the Employer in period 0. Throughout this article, we use the concept of Perfect-Bayesian equilibria and also verify that off-equilibrium beliefs survive standard refinements such as Cho and Kreps' (1987) intuitive criterion and mispricing. The usage of these criteria in a

\footnotetext{
${ }^{6}$ The Worker is ready to exchange the cost of effort for consumption in either the first or second period. This can be interpreted as a perfect credit market with a risk-free interest rate equal to 0 . This allows workers to transfer funds between periods.
} 
game without repetition where the informed party moves first is quite common in existing literature. ${ }^{7}$

\begin{tabular}{lll}
$t=0$ & \multicolumn{1}{c}{$t=1$} & \multicolumn{1}{c}{$t=2$} \\
\hline $\begin{array}{l}\text { Firm's type } \\
\text { is realized }\end{array}$ & $\begin{array}{l}\text { Employer offers } f_{1} \text { and } f \\
\text { to the Worker }\end{array}$ & $\begin{array}{l}\text { Employer offers } f_{2} \\
\text { to the Worker }\end{array}$ \\
$\begin{array}{l}\text { It is revealed to } \\
\text { the Employer }\end{array}$ & $\begin{array}{l}\text { If the offer is rejected } \\
\text { both parties get 0 } \\
\text { Otherwise the Worker } \\
\text { chooses } e_{1}\end{array}$ & $\begin{array}{l}\text { If the offer is rejected } \\
\text { both parties get 0 } \\
\text { Otherwise the Worker } \\
\text { chooses } e_{1}\end{array}$ \\
& $\begin{array}{l}\text { Project yields } r_{1} \\
\text { It is distributed to } \\
\text { the parties }\end{array}$ & $\begin{array}{l}\text { It is distributed } \\
\text { to the parties }\end{array}$ \\
& $\begin{array}{l}\text { The Worker decides how } \\
\text { many shares to sell }\end{array}$ & \\
&
\end{tabular}

\section{Figure 1. The sequence of events.}

\subsection{Symmetric information.}

This subsection provides some useful information about benchmark contracts when the Worker knows the firm's type. The relations describing the parties' decisions and payoffs are:

1) the second-period incentive constraint for the Worker:

$$
c \leq\left(f_{n}+f_{2}\right) \theta_{2}
$$

If it holds then $e_{2}=1$. Otherwise $e_{2}=0$.

2 ) the choice of $f_{2}$ by the Employer:

$$
f_{2}=\arg \max E\left[\left(1-f_{2}-f_{n}\right) r_{2}\right]
$$

3) the firm's market value at the end of the first period equals $V_{1}=\theta_{2}$ if the capital market believes that the Worker will supply $e_{2}=1$ (i.e. condition (4) holds) and zero otherwise.

\footnotetext{
${ }^{7}$ See, for instance, Diamond (1991, 1993), Myers and Majluf (1984) or Nachman and Noe (1994).
} 
4) the Worker's decision to sell shares:

$$
f_{n}=\arg \max \left[\left(f-f_{n}\right) V_{1}+\max \left\{0,\left(f_{n}+f_{2}\right) \theta_{2}-c\right\}\right]
$$

where $\left(f-f_{n}\right) V_{1}$ represents the value of shares sold by the Worker and $\max \left\{0,\left(f_{n}+f_{2}\right) \theta_{2}-c\right\}$ is the Worker's expected second-period payoff.

$5)$ the first-period incentive constraint for the Worker:

$$
c \leq f_{1} \theta_{1}+\left(f-f_{n}\right) V_{1}+\max \left\{0,\left(f_{n}+f_{2}\right) \theta_{2}-c\right\}
$$

6) the Employer's payoff is

$$
\Pi=\alpha_{1} r_{1}+\alpha_{2} r_{2}
$$

Given (3) we can write

$$
\Pi=\left(1-f_{1}\right) r_{1}+\left(1-f_{2}-f\right) r_{2}
$$

The Employer's problem is to maximize the expected value of (8):

$$
f_{1}, f=\arg \max E\left[\left(1-f_{1}\right) r_{1}+\left(1-f_{2}-f\right) r_{2}\right]
$$

Proposition 1. When information is symmetric:

$$
\begin{gathered}
f_{2}=c / \theta_{2} \\
c=f_{1} \theta_{1}+f \theta_{2} \\
V_{0}=E \Pi=\theta_{1}+\theta_{2}-2 c
\end{gathered}
$$

(all mathematical proofs are collected in the Appendix).

From (10), the fraction of second-period earnings offered to the Worker, is positively related to the cost of effort and negatively related to the firm's expected performance in that period. The logic behind (11) is similar. Eq. (12) implies that in the case of perfect information, the value of the firm (for the Employer) does not depend on the structure of the compensation contract (short-term versus long-term) offered to the Worker as long as conditions (10) and (11) hold. For instance one can have a contract with a very small $f_{1}$ as well as a contract with a very small $f$. 


\section{Signalling by the choice of compensation contract.}

Now suppose that the firm's type is the Employer's private information. We start with an efficient separating equilibrium where each type of Employer gets the first-best return (12). From (10) and (11) the strategy of the Employer can be completely described by only one variable. Take $f_{1}$ for convenience. Let $V_{k m}^{f_{1}}$ be the expected payoff to the Employer of type $k$ if strategy $f_{1}$ is played and the type is perceived by the Worker as type $m ; k, m \in\{g, b\}$. A separating equilibrium is a situation where type $g$ plays strategy $f_{1 g}$, type $b$ plays strategy $f_{1 b}$ and neither type has an incentive to mimic the other.

$$
\begin{aligned}
V_{g b}^{f_{1 b}} & \leq V_{g g}^{f_{1 g}} \\
V_{b g}^{f_{1 g}} & \leq V_{b b}^{f_{1 b}}
\end{aligned}
$$

Given limited liability and that if the contract is rejected, the payoff to the firm equals 0 , only accepted contracts are a part of equilibrium. Therefore, the value of $V_{k m}^{f_{1}}$ depends on the performance of type $k$ and the issued contracts which in turn depend on the Worker's beliefs about the firm's type (type $m$ ).

$$
V_{k m}^{f_{1}}=\left(1-f_{1 m}\right) \theta_{k 1}+\left(1-f_{2 m}-f_{m}\right) \theta_{k 2}
$$

where from (10) and (11):

$$
\begin{gathered}
f_{m}=\frac{c-f_{1 m} \theta_{m 1}}{\theta_{m 2}} \\
f_{2 m}=c / \theta_{m 2}
\end{gathered}
$$

We also know from Proposition 1 that $V_{x x}^{f_{1 x}}=v_{x}-2 c, x \in b, g$.

Lemma 1. If $\theta_{g t} \geq \theta_{b t}, t=1,2$ an efficient separating equilibrium does not exist.

Intuitively, if the good type $(g)$ has better performance in both periods then any contract issued by this type has a higher value than that issued by type $b$. Therefore the latter always mimics type $g$. Thus, a necessary condition for the existence of an efficient separating equilibrium is one of the following. Either $\theta_{g 1}>\theta_{b 1}$ and $\theta_{g 2}<\theta_{b 2}$ or $\theta_{g 2}>\theta_{b 2}$ and $\theta_{g 1}<\theta_{b 1}$. We will now continue with these two cases. The values of different contracts depend in different ways on the firm's expected performance in each period. Since 
each type performs differently in each period the value of contracts offered by different types are different. To avoid mimicking, type $g$ will offer contracts which put more weight on the earnings in the period when it underperforms type $b$. Thus, in the first case, we expect that type $g$ will offer a contract with a large number of stock options while in the second case it will offer a large bonus. In a separating equilibrium, type $b$ will offer the opposite contracts.

The analysis of conditions (13) and (14) leads to the following result.

Proposition 2. If $\theta_{g 1}>\theta_{b 1}$ and $\theta_{g 2}<\theta_{b 2}$ then a separating equilibrium exists if and only if

$$
\frac{\theta_{g 1} \theta_{b 2}-\theta_{b 1} \theta_{g 2}}{\theta_{g 1}-\theta_{b 1}} \geq 2 c
$$

Furthermore if a separating equilibrium exists then

$$
f_{1 b} \geq f_{1 g}
$$

2) if $\theta_{g 2}>\theta_{b 2}$ and $\theta_{g 1}<\theta_{b 1}$ then a separating equilibrium exists if and only if

$$
\frac{\theta_{b 1}}{\theta_{g 1}}+\frac{\theta_{b 2}}{\theta_{g 2}} \geq 2
$$

Furthermore if a separating equilibrium exists then

$$
f_{1 b} \leq f_{1 g}
$$

Proposition 2 implies that firms which have better performance in the first period and weaker performance in the second period will offer a lower fraction of short-term bonuses to the Worker. Consider the interpretation of conditions (18) and (19). Two ideas underline the analysis below. First, when the difference between firms' total values is large enough a separating equilibrium does not exist. This is because the type with a low total value will mimic the high value type. A large difference in the firms' rates of earnings growth contributes to the existence of a separating equilibrium by making it possible for $g$ to design debt claims which will not be mimicked by $b$. To see this let us rewrite (19) as follows:

$$
\begin{gathered}
\frac{v_{b} v_{g}\left(r_{b}-r_{g}\right)}{v_{g}\left(1+r_{b}\right)-v_{b}\left(1+r_{g}\right)} \geq 2 c \\
\frac{v_{b}\left(r_{g}+r_{b}\right)\left(1+r_{g}\right)}{v_{g} r_{g}\left(1+r_{b}\right)} \geq 2
\end{gathered}
$$


where $r_{x}=\theta_{x 2} / \theta_{x 1}$ is the rate of earnings growth for type $x$. The condition $r_{x}>1$ means that a firm has an increasing earnings profile, $r_{x}<1$ and $r_{x}=1$ means that the firm has a decreasing or flat earnings profile respectively.

Corollary 1. A separating equilibrium exists if and only if the following holds: 1) the extent of asymmetric information regarding firms' total values is sufficiently small and; 2) the extent of asymmetric information regarding firms' performance profiles over time is sufficiently large.

Figure 1 illustrates Corollary 1. Here $r_{g}=1.5, v_{g}=1.6, \theta_{g 1}=0.64, \theta_{g 2}=$ 0.96 and $c=0.4$. The figure shows the values of $r_{b}$ and $v_{b}$ for which separating equilibriums may exist. In the space between the thick lines $\left(F_{2}\right)$ a separating equilibrium does not exist. In $F_{1}$ and $F_{3}$ a separating equilibrium exists. Note that for any value of $v_{b}$ a separating equilibrium exists if $r_{b}$ differs sufficiently from $r_{g}$ and for any $r_{b}$ a separating equilibrium exists if $v_{b}$ is high enough (close to $v_{g}$ ). In other words, a separating equilibrium exists if asymmetric information about rate of earnings growth is more important than that concerning the firms' total values.

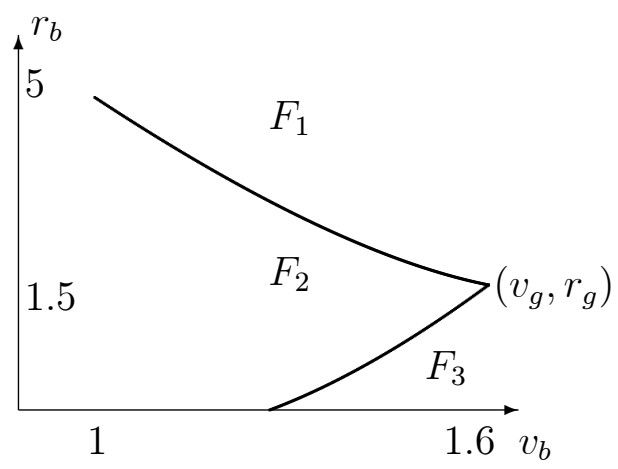

Figure 1. Separating equilibria.

\section{Pooling equilibria.}

Let us turn to the analysis of pooling equilibria where both types play the same strategies in both periods: $f_{1}, f, f_{2}{ }^{8}$ The relations describing the par-

\footnotetext{
${ }^{8}$ Note that a separation in the second period cannot exist after pooling in the first. Indeed, suppose the opposite is true and in the second period one type offers a lower fraction of earnings to the Worker than the other type. If this offer is accepted, the other type will obviously mimic this strategy. Otherwise this strategy cannot be a part of equilibrium given the limited liability of the Employer.
} 
ties' decisions and payoffs are:

1) the second-period incentive constraint for the Worker:

$$
c \leq\left(f_{n}+f_{2}\right)\left(\mu_{2} \theta_{g 2}+\left(1-\mu_{2}\right) \theta_{b 2}\right)
$$

where $\mu_{2}$ is the Worker's belief at the beginning of period 2 that the type is g. According to Bayes' rule:

$$
\begin{gathered}
\mu_{2}=\frac{\mu \theta_{g 1}}{\mu \theta_{g 1}+(1-\mu) \theta_{b 1}} \text { if } r_{1}=1 \\
\mu_{2}=\frac{\mu\left(1-\theta_{g 1}\right)}{\mu\left(1-\theta_{g 1}\right)+(1-\mu)\left(1-\theta_{b 1}\right)} \text { if } r_{1}=0
\end{gathered}
$$

2) the firm's market value at the end of the first period equals $V_{1}=$ $\mu_{2} \theta_{g 2}+\left(1-\mu_{2}\right) \theta_{b 2}$ if the capital market believes that the Worker will supply $e_{2}=1$ (i.e. condition (22) holds) and zero otherwise.

3) the Worker's decision to sell shares:

$$
f_{n}=\arg \max \left[\left(f-f_{n}\right) V_{1}+\max \left\{0,\left(f_{n}+f_{2}\right)\left(\mu_{2} \theta_{g 2}+\left(1-\mu_{2}\right) \theta_{b 2}-c\right\}\right]\right.
$$

where $\left(f-f_{n}\right) V_{1}$ represents the value of shares sold and $\max \left\{0,\left(f_{n}+f_{2}\right)\left(\mu_{2} \theta_{g 2}+\right.\right.$ $\left.\left(1-\mu_{2}\right) \theta_{b 2}-c\right\}$ is the Worker's expected second-period payoff.

4) the first-period incentive constraint for the Worker:

$$
c \leq f_{1} \theta_{1}+E\left[\left(f-f_{n}\right) V_{1}+\max \left\{0,\left(f_{n}+f_{2}\right)\left(\mu_{2} \theta_{g 2}+\left(1-\mu_{2}\right) \theta_{b 2}-c\right\}\right]\right.
$$

5) the payoff to the Employer of type $x$ is

$$
V=\left(1-f_{1}\right) \theta_{x 1}+\left(1-f_{2}-f\right) \theta_{x 2}
$$

Lemma 2. If a pooling equilibrium exists then

$$
\begin{gathered}
c=f_{1} \widehat{\theta_{1}}+f \widehat{\theta_{2}} \\
f_{2} \equiv f_{2}\left(r_{1}\right)=c / \widetilde{\theta_{2}}\left(r_{1}\right)
\end{gathered}
$$

where

$$
\widetilde{\theta_{2}}\left(r_{1}\right)=\mu_{2} \theta_{g 2}+\left(1-\mu_{2}\right) \theta_{b 2}
$$

Note that in contrast to the symmetric information case, $f_{2}$ depends on $\mu_{2}$ and $r_{1}$ because the Worker updates his beliefs about the firm's type after 
observing first-period earnings. From (27) and (26) the equilibrium strategy can be completely described by only one variable. Take $f_{1}$ for convenience. Let $V_{x}^{f_{1}}$ be the expected payoff to the Employer of type $x$ in the case of a pooling equilibrium with $f_{1}$. A pooling equilibrium is a situation where both types play strategy $f_{1}$, off-equilibrium worker's beliefs about observing an off-equilibrium strategy $f_{1 o f f}$ are that the firm is type $g$ with probability $\mu_{o f f}\left(f_{1 o f f}\right)$ and

$$
V_{x}^{f_{1}} \geq V_{x}^{f_{10 f f}}, x \in b, g
$$

We have:

$$
V_{g}^{f_{1}}=\theta_{g 1}\left(1-f_{1}+\left(1-f_{2}(1)-f\right) \theta_{g 2}\right)+\left(1-\theta_{g 1}\right)\left(1-f_{2}(0)-f\right) \theta_{g 2}
$$

where $f_{2}\left(r_{1}\right)$ is given by $(27)$ and from $(26)$

$$
f=\left(c-f_{1} \widehat{\theta_{1}}\right) / \widehat{\theta_{2}}
$$

In a pooling equilibrium type $g$ is underpriced. Thus, we will look for a pooling equilibrium which minimizes the mispricing of type $g$. The mispricing is the difference between the Employer's first-best return $\theta_{g 1}+\theta_{g 2}-2 c$ and its equilibrium payoff $V_{g}^{f_{1}}$.

Proposition 3. Pooling with $f_{1}=\frac{c}{\widehat{\theta_{1}}}$ minimizes mispricing if and only if $\frac{\theta_{g 2}}{\theta_{b 2}} \geq \frac{\theta_{g 1}}{\theta_{b 1}}$; pooling with $f_{1}=\frac{\max \left\{0, c-\left(1-c / \max \left\{\widetilde{\theta_{2}}(0), \widetilde{\theta_{2}}(1)\right\}\right) \widehat{\left.\theta_{2}\right\}}\right.}{\widehat{\theta_{1}}}$ minimizes mispricing if and only if $\frac{\theta_{g 2}}{\theta_{b 2}}<\frac{\theta_{g 1}}{\theta_{b 1}}$.

The intuition behind Proposition 3 is that if $\theta_{g 2} / \theta_{b 2} \geq \theta_{g 1} / \theta_{b 1}$ the extent of uncertainty regarding long-term cash flows is large. In this case optimal contracts put as much weight as possible on the first period (from (26) the maximal value of $f_{1}$ is $\left.c / \widehat{\theta_{1}}\right)$ to reduce the "lemon" effect of asymmetric information and vice versa.

Finally note that, if an inefficient separating equilibrium exists (one where type $b$ has its first-best payoff in equilibrium while type $g$ is undervalued because it offers a larger annual bonus (or larger fraction of stock) than in the symmetric information case to avoid being mimicked by $b$ ) then mispricing is larger than in a pooling equilibrium described in Proposition 3. Proof of this is omitted for brevity but is available upon request. 


\section{Implications.}

(i) The present paper argues that asymmetric information regarding the timing of a firm's performance profile over time may affect the structure of earnings-based compensation contracts for employees. In particular, it explains why it motivates firms to issue stock options for employees (versus annual bonuses). From Proposition 1, a firm's compensation policy is irrelevant when information is symmetric. It is relevant when information is asymmetric as implied by Propositions 2 and 3 .

Jensen and Meckling (1976) argue that earnings-based compensation links an employee's wealth with a firm's value thus mitigating moral hazard and agency problems. Since then numerous extensions of this theory have been developed. However, we have not found one that is focused on explaining the link between the structure of earnings-based compensation and the future dynamics of earnings. Also note that Yermack $(1995,1997)$ analyzes the determinants of top executives options grants and concludes that agency theory does not explain observed data. Oyer and Schaeffer (2005) do not find any support for moral hazard explanations for why firms issue options to employees. Another theory is based on employees' risk-aversion. It argues that options, by introducing convexity into their payoffs, can improve otherwise conservative decision-making by employees. However, this idea has been challenged by Carpenter (2000) and Ross (2004), who argue that options can actually increase managers' aversion to risk. Among other approaches note: inducing employees to sort, helping firms retain employees and tax consideration. While all of them find some empirical support, none is considered a major idea behind the usage of stock options in theoretical literature.

(ii) The model predicts that short-term incentives will prevail if the extent of asymmetric information in the first period is lower than that in the second period and vice versa. This is implied by Proposition 3. $\theta_{g 2} / \theta_{b 2}<\theta_{g 1} / \theta_{b 1}$ means that the extent of uncertainty about future earnings is lower than that in the first period. Instead, if $\theta_{g 2} / \theta_{b 2}>\theta_{g 1} / \theta_{b 1}$, stock options will prevail. In addition to the evidence provided in the introduction, note that Hayes and Schaeffer (2000) find that incentive plans become relatively more reliant on insiders' private information about firms' future performance when the precision of current accounting information decreases.

(iii) It follows from Proposition 2 and Corollary 1 that if the extent of asymmetric information regarding firms' total values is small enough (compared to the extent of asymmetric information regarding the performance 
profile over time) then a separating equilibrium may exist. This equilibrium implies that firms which offer higher fractions of equity (through options) in their compensation contracts have higher operating performance in the short-run and lower operating performance in the long-run (as compared to firms which offer fewer options). This is type $b$ if $\theta_{g 2}>\theta_{b 2}$ and $\theta_{g 1}<\theta_{b 1}$ and is type $g$ if $\theta_{g 2}<\theta_{b 2}$ and $\theta_{g 1}>\theta_{b 1}$. Empirical literature produces different evidence regarding the impact of compensation contracts on firms' future operating performance. However, the following papers are noteworthy. Yermack (1997) shows that firms issuing stock options for employees outperform other firms shortly after issue while there is no significant difference in the long run. Cheng and Farber (2006) find that among firms which experience financial restatement those which decrease the portion of stock options in managers' compensation contracts perform better in the long term. It has also been observed (Gilson and Vetsuypens, 1994) that firms in financial distress (with a projected decrease in cash flows) offer a higher fraction of stock options in their compensation structure and a lower fraction of bonus or cash-based compensation.

As an alternative explanation for why using options for employees may lead to long-term underperformance, Gao and Shrieves (2002) argue that a high proportion of options in compensation contracts provides an incentive to engage in earnings manipulation by pumping earnings in periods when their portfolios of options are large. Thus, less effort will be allocated to production activities. This argument only works if agents are not able to rationally anticipate opportunistic behavior of this kind. In this case, managers and employees can mislead the stock market by dressing earnings. We share the idea that insiders can be involved in earnings management leading to asymmetric information about the firm's performance profile over time. However, our explanation is based on completely rational agents.

Issuing more options to workers leads to an increase in equity capital. Thus, our findings are also consistent with the well-known phenomenon that firms issuing equity underperform other firms in the long run and outperform them in the short run (see, among others, Jain and Kini (1994) and Loughran and Ritter (1997)).

While the empirical literature mentioned above provides some data which is similar to the spirit of the present paper, a complete test of the results must be based on incorporating the temporal distribution of informational asymmetry into the empirical analysis of compensation contracts. The key problem is to find proxies for the distribution of informational asymmetry. 
One can use, for example, the degree to which a firm is established. Possible proxies for this are the firm's age and size. The younger and smaller the firm, the more asymmetry one would expect regarding short-term cash flows. Another proxy for the temporal distribution of informational asymmetry is industry membership. Firms with large R\&D expenditures and significant growth opportunities (Tobin's Q can be used as a proxy for growth opportunities; it can be calculated, for instance, as book value of assets minus book value of equity plus market value of equity divided by book value of assets) can be seen as ones with low short-term asymmetry and high long-term asymmetry. Firms in industries with high cyclicality in short-term demand, such as consumer durables and housing, should exhibit relatively higher levels of informational asymmetry regarding short-term prospects. Most data indicated above are available from COMPUSTAT or Standard and Poor's database. Also, firms with strict reporting requirements should have relatively less asymmetry regarding the short term because accounting data has relatively more predictive power for short-run rather than long-run performance (see, for example, Brown and Rozeff (1979) and Bushman et al. $(2004)){ }^{9}$

For firms facing relatively more informational asymmetry in the long term bonuses are a more likely form of compensation. Stock options are most likely to be observed when the degree of informational asymmetry is fairly large regarding the short-run and fairly small regarding distant cash flows (one can gather data on employees' compensation from, for example, Standard and Poor's Execucomp, ProxyBase dataset of Hewitt associates or Surveys conducted by the National Center for Employees Ownership). These hypotheses can be empirically investigated using polychotomous dependent variable technique such as multinominal logit/probit models (see, for example, Kennedy (2003), Chapter 15). Further, the tightening of accounting standards would tend, through the imposition of increased reporting, to decrease informational asymmetry regarding short-term cash flows, leading us to predict that such changes would tend to increase corporate dependence on annual bonuses.

\footnotetext{
${ }^{9}$ Also note that the conservative firms, i.e. firms that incorporate "bad" news into accounting numbers more quickly than "good" news can be seen as ones with low shortterm asymmetry and high long-term asymmetry because, as shown by Basu (1997), "bad" news has more of an effect on short-term earnings while the effect of "good" news is generally more persistent over time. The degree of conservatism can be measured, for instance, by the degree of legal liabilities of auditors.
} 
The result of Proposition 2 that firms using more stock options in their compensation packages have lower long-term expected performance relative to other firms can be tested using the techniques similar to those in Jain and Kini (1994), Yermack (1997), Loughran and Ritter (1997) or Cheng and Farber (2006). More challenging would be to test the conditions for the existence of a separating equilibrium, another result of this proposition. This may indicate the conditions under which one would observe the previous phenomenon (underperformance of firms issuing more stock options) more frequently. As predicted by Proposition 2, this is the case when asymmetry regarding the magnitude of firms' expected earnings is relatively small, while the asymmetry regarding the timing of earnings is relatively large. The extent of asymmetric information regarding the firms' total values should be inversely related to the market liquidity of firms' shares (see, for instance, Bharath, Pasquariello, and $\mathrm{Wu}(2006)$ ). The latter can be measured using the following proxies: the bid-ask spread, return-volume coefficient and the probability of informed trading (Easley, Kiefer, O'Hara and Peperman (1996)). The data can be taken form CRSP NYSE/AMEX database. One can use the spread in the forecasts of future earnings (long-term spread versus short-term spread) as a proxy for asymmetric information about the timing of earnings. A lack of consensus among the analysts about the future earnings of the followed firm suggests a lack of firm-specific information. This measure is available from Institutional Brokers Estimate System (I/B/E/S). I/B/E/S provides (among others) forecasts dispersion for one-year ahead earnings but also for the five-year earnings. Also, as mentioned above, firms manipulating earnings can be seen as ones with a high degree of asymmetric information about the timing of earnings since earnings management can often be seen as a redistribution of earnings between periods rather than accounting fraud (Degeorge et al, 1999).

An interesting direction for future empirical research would be to generalize the notion of temporal distribution of informational asymmetry with the goal of constructing better proxies for the temporal distribution. Under one scenario, the evolution of the variance of firm cash flows can act as a proxy for the distribution of asymmetric information. This would be the case when the average quality of inside information is the same for all firm types across all dates. In this case, increased cash flow volatility over time, which could be estimated using GARCH techniques or the term structure of implied volatility estimated using option prices, would imply greater information asymmetry regarding long-term cash flows. Conversely, decreasing cash 
flow variance over time would imply lower informational asymmetry regarding long-term cash flows. In this fashion one could relate the term structure of volatility to the structure of earnings-based compensation contracts.

\section{Conclusion.}

Lambert (2001) suggested that the private insider information may affect the structure of compensation contracts. This paper analyzes the structure of earnings-based compensation contracts (annual bonuses versus stock options) when employers have private information about the firms' qualities and workers are subject to moral hazard. The model predicts that short-term incentives will prevail if the extent of short-term asymmetric information is low relative to long-term asymmetric information. It is also shown that among firms with potentially high degrees of asymmetric information regarding the timing of earnings (for instance, among firms involving in earnings management) those offering more stock options in compensation packages outperform in the short-run and underperform in the long-run. A discussion of empirical implications of these results is provided.

Appendix.

Proof of Proposition 1. Under symmetric information the first-best solution can be obtained in the following manner. First, note that in equilibrium (4) and $e_{2}=1$ cannot hold simultaneously with $c>f_{2} \theta_{2}$. In this case, $V_{1}=\theta_{2}$ and from (6) the Worker's payoff is $\left(f+f_{2}\right) \theta_{2}-c$ which is less than $f \theta_{2}$. Thus, the Worker will sell their shares at the beginning of $t=2$ and chose $e_{2}=0$. Therefore, if the second-period constraint is satisfied in equilibrium then $c \leq f_{2} \theta_{2}$. From (5) the firm is interested in minimizing $f_{2}$ by making sure that (4) holds. If (4) does not hold then from (5) the firm's second-period payoff is 0 . Therefore, $f_{2}=c / \theta_{2}-f_{n}$. Together with $c \leq f_{2} \theta_{2}$ this implies $f_{n}=0$ and $f_{2}=c / \theta_{2}$. From (7) $c=f_{1} \theta_{1}+f \theta_{2}$ and from (9) $V_{0}=E \Pi=\theta_{1}+\theta_{2}-2 c$. End proof.

Proof of Lemma 1. Suppose the opposite is true and such an equilibrium exists. Let $g$ play the strategy $f_{1 g}$. It follows from (16), (17) and $\theta_{g t}>\theta_{b t}$ that $V_{b g}^{f_{1 g}}=\left(1-f_{1 g}\right) \theta_{b 1}+\left(1-f_{2 g}-f_{g}\right) \theta_{b 2}>\theta_{b 1}+\theta_{b 2}-2 c$. End proof.

Proof of Proposition 2. First consider $\theta_{g 2}>\theta_{b 2}$ and $\theta_{g 1}<\theta_{b 1}$. Proof of necessity. From (15), (16) and (17), the incentive constraint (13) for type $g$ 
holds if and only if:

$$
f_{1 b} \leq A
$$

where

$$
A=2 c\left(\theta_{g 2}-\theta_{b 2}\right) /\left(\theta_{b 1} \theta_{g 2}-\theta_{g 1} \theta_{b 2}\right)
$$

The incentive constraint (14) for type $b$ holds if and only if:

$$
f_{1 g} \geq A
$$

This proves $f_{1 b} \leq f_{1 g}$. Now from (1) and (16) we have:

$$
f_{1 g} \leq c / \theta_{g 1}
$$

From (32) and (33) $c / \theta_{g 1} \geq A$. By (31) this can be rewritten as the condition (19).

Sufficiency. Suppose that (19) holds and consider a situation with $f_{1 g}=$ $c / \theta_{g 1}$ and $f_{1 b}=0$. The incentive constraint for $b$ holds because of (19) and the above argument. The incentive constraint for $g$ holds noting that $A>0$.

Now consider $\theta_{g 2}<\theta_{b 2}$ and $\theta_{g 1}>\theta_{b 1}$. Necessity. From (15), the incentive constraint (13) for type $g$ holds if and only if:

$$
f_{1 b} \geq A
$$

The incentive constraint (14) for type $b$ holds if and only if:

$$
f_{1 g} \leq A
$$

This proves $f_{1 b} \geq f_{1 g}$. From (2) and (17) we have:

$$
f_{g} \leq 1-c / \theta_{g 2}
$$

Now from (1), (16) and (36):

$$
f_{1 g} \geq\left(2 c-\theta_{g 2}\right) / \theta_{g 1}
$$

From (35) and (37)

$$
\left(2 c-\theta_{g 2}\right) / \theta_{g 1} \leq A
$$

This can be rewritten as (18).

Sufficiency. Suppose that (18) holds and consider a situation with $f_{1 g}=$ $\left(2 c-\theta_{g 2}\right) / \theta_{g 1}$ if $2 c>\theta_{g 2}$ and $f_{1 g}=0$ if $2 c \leq \theta_{g 2}$ and $f_{1 b}=c / \theta_{b 1}$. The 
incentive constraint for $b$ holds because of (18). The incentive constraint for $g$ holds noting that $c / \theta_{b 1}>A$ because $\frac{\theta_{g 1}}{\theta_{b 1}}+\frac{\theta_{g 2}}{\theta_{b 2}} \geq 2$. End proof.

Proof of Corollary 1. Consider the case $r_{g} \geq r_{b}$. First we show that if a separating equilibrium exists then $r_{g} \geq 1$. From Proposition 2, if a separating equilibrium exists then (21) holds. Since the left side of (21) is increasing in $v_{g}$ it should also be $\frac{\left(r_{g}+r_{b}\right)\left(1+r_{g}\right)}{r_{g}\left(1+r_{b}\right)} \geq 2$. This implies $r_{g} \geq 1$. Take the partial derivatives of left of (21). We have: $\partial(.) / \partial r_{b}<0 ; \partial(.) / \partial r_{g}>0 ; \partial(.) / \partial v_{b}>$ $0 ; \partial(.) / \partial v_{g}<0$. This implies that (21) holds if: 1) $r_{b}$ is sufficiently small (other parameters being equal); 2) $v_{b}$ is sufficiently large; 3) $r_{g}$ is sufficiently large and; 4) $v_{g}$ is sufficiently small. Now consider the case $r_{b}>r_{g}$. From Proposition 2, if a separating equilibrium exists then (20) holds. The rest follows from analyzing the partial derivatives of left side of (20). End proof.

Proof of Lemma 2. In equilibrium (22) cannot hold simultaneously with $c>f_{2}\left(\mu_{2} \theta_{g 2}+\left(1-\mu_{2}\right) \theta_{b 2}\right)$. In this case $V_{1}=\mu_{2} \theta_{g 2}+\left(1-\mu_{2}\right) \theta_{b 2}$ and from (23) the Worker's payoff is $\left(f+f_{2}\right)\left(\mu_{2} \theta_{g 2}+\left(1-\mu_{2}\right) \theta_{b 2}\right)-c$ which is less than $f\left(\mu_{2} \theta_{g 2}+\left(1-\mu_{2}\right) \theta_{b 2}\right)$. Thus, the Worker will sell their shares at the end of $t=$ 1 and chose $e_{2}=0$. Therefore, if the second-period constraint is satisfied in equilibrium then $c \leq f_{2}\left(\mu_{2} \theta_{g 2}+\left(1-\mu_{2}\right) \theta_{b 2}\right)$. Now consider $f_{2}$. Both types are better off with $f_{2}$ being as small as possible. To achieve this they must make sure that (22) holds. If (22) does not hold then, from (5), the firm's secondperiod payoff is 0 . Therefore, $f_{2}=c /\left(\mu_{2} \theta_{g 2}+\left(1-\mu_{2}\right) \theta_{b 2}\right)-f_{n}$. Together with $c \leq f_{2}\left(\mu_{2} \theta_{g 2}+\left(1-\mu_{2}\right) \theta_{b 2}\right)$ this implies $f_{n}=0$ and $f_{2} \equiv f_{2}\left(r_{1}\right)=c / \tilde{\theta}_{2}\left(r_{1}\right)$, where $\widetilde{\theta_{2}}\left(r_{1}\right)=\mu_{2} \theta_{g 2}+\left(1-\mu_{2}\right) \theta_{b 2}$. In contrast to the symmetric information case, $f_{2}$ depends on $\mu_{2}$ and $r_{1}$. From $(24) c=f_{1} \widehat{\theta_{1}}+f \widehat{\theta_{2}}$. End proof.

Proof of Proposition 3. From (29) $\frac{\partial V_{g}^{f_{1}}}{\partial f_{1}}=-\theta_{g 1}+\frac{\widehat{\theta_{1}} \theta_{g 2}}{\widehat{\theta_{2}}}$. Thus, if $\frac{\theta_{g 2}}{\theta_{b 2}} \geq \frac{\theta_{g 1}}{\theta_{b 1}}$, $f_{1}$ should be maximized. From $(26)$ it is $f_{1}=\frac{c}{\widehat{\theta_{1}}}$. Otherwise $f_{1}$ should be minimized. A minimal $f_{1}$ corresponds to a maximal $f$. From (2) and (27) $f \leq$ $1-c / \max \left\{\widetilde{\theta_{2}}(0), \widetilde{\theta_{2}}(1)\right\}$. This condition, together with $(1)$ and (26), implies $f_{1} \geq \frac{\max \left\{0, c-\left(1-c / \max \left\{\widetilde{\theta_{2}}(0), \widetilde{\theta_{2}}(1)\right\}\right) \widehat{\theta_{2}}\right\}}{\hat{\theta}_{1}}$. To prove that these pooling equilibria exist and that they satisfy the Cho-Kreps intuitive criterion, first note that since a separating equilibrium minimizes mispricing compared to pooling we only consider the cases when (18) and (19) do not hold. Also, a strategy where at least one incentive constraint for the Worker is not satisfied is always dominated, for all types of Employers, by a strategy where both incentive constraints hold (given limited liability). It holds, whatever the Worker's beliefs are, when they observe such a strategy out off equilibrium. Thus, no 
type of Employer will deviate to such a strategy. Therefore, we consider only the off-equilibrium strategies for which both incentive constraints hold (for some beliefs). For this set of strategies the off-equilibrium beliefs supporting equilibrium are that when observing strategy $j_{\text {off }}$ the Worker believes that the type is $b$. Thus, type $b$ does not deviate from the equilibrium because its equilibrium payoff exceeds its first-best payoff. Also, type $g$ does not deviate. To see this note that from (18), (19) and (29), $\partial V_{g}^{f_{1}} / \partial \mu>0$. The off-equilibrium beliefs satisfy the Cho-Kreps intuitive criterion because type $b$ has the potential to earn more than its equilibrium payoff if the beliefs are that the type is $g$ since $\partial V_{b}^{f_{1}} / \partial \mu>0$. End proof.

\section{References}

Akerloff, G. (1970). "The Market for Lemons: Quality Uncertainty and the Market Mechanism", Quarterly Review of Economics, Vol. 74, No. 3, pp. 488-500.

Azariadis, C. (1983). "Employment with Asymmetric Information", Quarterly Journal of Economics, Vol. 98, Supplement, pp. 157-72.

Basu, S. (1997). "The Conservatism Principle and the Asymmetric Timeliness of Earnings", Journal of Accounting and Economics, Vol. 24, pp. 3-27.

Berkovitch, E. (1986). "Implicit Labor Contract to Explain Turnover", Journal of Labor Economics, Vol. 4, No. 3, pp. 341-354.

Bharath, S., P. Pasquariello, and G. Wu. (2006). "Does Asymmetric Information Drive Capital Structure Decisions?", SSRN working paper.

Brown, L., and Rozeff. (1979). "The Predictive Value of Interim Reports for Improving Forecasts of Future Quarterly Earnings", The Accounting Review, Vol. 54, pp. 585-591.

Bushman, R., Q. Chen, E. Engel, \& A. Smith. (2004). "Financial Accounting Information, Organizational Complexity and Corporate Governance Systems", Journal of Accounting and Economics, Vol. 37, pp. 167-201.

Carpenter, J. (2000). "Does Option Compensation Increase Managerial Risk Appetite?", Journal of Finance, Vol. 55, pp. 2311-2331.

Cheng, Q., and D. Farber. (2006). "Earnings Restatements, Changes in CEO Compensation, and Firm Performance", Sauder School of Business Working Paper.

Coates, R. (1972). "The Predictive Content of Interim Reports-A Time Series Analysis", Journal of Accounting Research, Vol. 10, pp. 132-144.

Cho, I. K., \& Kreps, D. (1987). "Signalling Games and Stable Equilibria", Quarterly Journal of Economics, Vol. 102, No. 2, pp. 179-221.

Degeorge, F., Patel, J., and Zeckhauser, R. (1999). "Earnings Management to Exceed Thresholds", Journal of Business, Vol. 72, pp. 1-33. 
Dial, J., and K. Murphy. (1995). " Incentives, Downsizing, and Value Creation at General Dynamics", Journal of Financial Economics, Vol. 37, pp. 261-314.

Diamond, D. (1991). "Debt Maturity Structure and Liquidity Risk", Quarterly Journal of Economics, Vol. 106, pp. 709-737.

Diamond, D. (1993). "Seniority and Maturity of Debt Contracts", Journal of Financial Economics, Vol. 33, pp. 341-368.

Easley, D. Kiefer, N., O'Hara, M., and J. Peperman. (1996). "Liquidity, Information, and Infrequently Traded Stocks", Journal of Finance, Vol. 51, pp. 1405-1436.

Gao, P., and Shrieves. (2002). "Earnings Management and Executive Compensation: A Case of Overdose of Option and Underdose of Salary?", working paper.

Gilson, S., and M. Vetsuypens. (1994). "Creating Pay-for-Performance in Financially Troubled Companies", Journal of Applied Corporate Finance, Vol. 6, No. 4, pp. 81-93.

Handy, F., and E. Katz. (1998). "The Wage Differential Between Non-profit Institutions and Corporations: Getting More by Paying Less?", Journal of Comparative Economics, Vol. 26, pp. 246-261.

Hayes, R., and S. Schaefer. (2000). "Implicit Contracts and the Explanatory Power of Top Executive Compensation for Future Performance", RAND Journal of Economics, Vol. 31, No. 2, pp. 273-293.

Jain, B., \& Kini, O. (1994). "The Post-Issue Operating Performance of IPO Firms", Journal of Finance, Vol. 49, No.5, pp. 1699-1726.

Jensen, M., and W. Meckling. (1976). "Theory of the Firm: Managerial Behavior, Agency Costs and Ownership Structure", Journal of Financial Economics, Vol. 3, pp. 305-360.

Kennedy, P. (2003). A Guide to Econometrics, 5th Ed. MIT Press.

Lambert, R. (2001). "Contracting Theory and Accounting", Journal of Accounting and Economics 32.

Loughran, T., \& Ritter, J. (1997). "The Operating Performance of Firms Conducting Seasoned Equity Offerings", Journal of Finance, Vol. 52, No. 5, pp. 1823-1850.

Miglo, A.(1997). "Debt-equity Choice as a Signal of Earnings Profile over Time", Quarterly Review of Economics and Finance Vol. 47, pp. 69-93.

Miglo, A., and N. Zenkevich. (2006). "Non-hierarchical Signalling: Two-stage Financing Game", International Journal of Mathematics, Game Theory and Algebra, Vol. 15, No. 3. Reprinted in Game Theory and Applications, Volume 11, Nova Science Publishers Inc., NY, 2006. Editors: L. Petrosjan and V. Mazalov.

Murphy, K. (1999). "Executive Compensation," in Orley Ashenfelter and David Card (eds.), Handbook of Labor Economics, Vol. 3, North Holland.

Myers, S., and N. Majluf. (1984). "Corporate Financing and Investment Decisions 
When Firms Have Information That Investors Do not Have", Journal of Financial Economics, Vol. 13, pp. 187-221.

Nachman, D., and T. Noe. (1994). "Optimal Design of Securities Under Asymmetric Information", Review of Financial Studies, Vol. 7, No. 1, pp. 1-44.

Oyer, P., and S. Schaefer. (2005). "Why Do Some Firms Give Stock Options To All Employees?: An Empirical Examination of Alternative Theories", Journal of Financial Economics, Vol. 76, pp. 99-133.

Ross, S. (2004). "Compensation, Incentives, and the Duality of Risk Aversion and Riskiness", Journal of Finance, Vol. 59, pp. 207-225.

Salop, J., and S. Salop. (1976). "Self-Selection and Turnover in the Labor Market", Quarterly Journal of Economics, Vol. 90, No. 3, pp. 619-627.

Spence, M. (1973). "Job Market Signaling", Quarterly Journal of Economics, Vol. 87, No. 2, pp. 355-74.

Yermack, D. (1995). "Do Corporations Award Stock Options Effectively?", Journal of Financial Economics, Vol. 39, pp. 237-269.

Yermack, D. (1997). "Good Timing: CEO Stock Options Awards and Company News Announcements", Journal of Finance, Vol. 52, pp. 449-476. 